\title{
Impact of Perceived Discrimination and Resultant Stress on Innovative Work Behavior Moderated By Spirituality among Female Emoployees in Private Banks of Rawalpindi
}

\author{
Samreen Fatima Malik \\ Advance Research Methodology
}

\begin{abstract}
The objective of this research paper is to investigate the negative effects of perceived discrimination in the form of workplace stress on employee innovative work behavior among the female employees working in banking sector of Rawalpindi. Using a time lagged design, the effects of PD and its corresponding stress was tested on IWB, moderated by spirituality. Analyses involved data collected from 170 female's bankers. The results show that PD was positively related to workplace stress while workplace stress negatively affected IWB. As hypothesized, moderating effects of spirituality on stress to IWB were verified wherein it was proved that spirituality can mitigate the negative impact of stress on IWB. Therefore, we can conclude that fair treatment and better self-esteem improves productivity among employees. The study of moderating influence of Spirituality in Pakistani environment has proved to be a helpful contextual factor in buffering stress and promoting a healthy and productive work environment.
\end{abstract}

\section{INTRODUCTION}

The innovation plays a very important and central role in the long term survival of an organization (Ancona \& Caldwell, 1987). Since innovation is characterized by discontinuous activities rather than unique, successive stages (Schroeder, Van de Ven, Scudder, \& Polley, 1989), individuals can to be expected to be involved in any combination of these behaviors at any given time. Innovation is the production and generation of useful ideas and idea execution (Kanter, 1988; Van de Ven, 1986). Thus, innovation also involves the adaptation of products or processes from outside an organization.

Empirical evidences have shown a strong link of employees' innovative work behavior with desirable organizational outcomes. For example, IWB has been proved as the key antecedent to productivity, competitive advantage and organizational effectiveness. The critical nature of IWB motivated various researchers to know the factors help to encourage innovative work behavior among employees and also to know the factors postulating hindrances towards innovative work behavior. For example, personality types, leadership style, working environment and group cohesion has been proved as the key causes of innovative work behavior (Kanter, 1983; Pelz \& Andrews, 1966). Whereas, abusive supervision, job stressors and workload have been characterized as the key hindrances towards innovative work behavior (Hon, 2011; Hon and Leung, 2011).

Workplace stress has been highlighted as an obstructing cause impeding creativity and out of box approach (O'Neil and Davis, 2010). Employees working in stressful environment spend their energies in buffering stress and eliminate causes of stress. Specifically considering women who are perceived to be emotionally weak, may be more vulnerable to stress. They are 
more likely to be exposed to gender discrimination from male officers and supervisors, which may increase their level of stress and burnout (Martin, 1992). Especially in developing countries marked high at power distances, women have to struggle in all spheres of life. Ellison and Genz (1983) found that features of the work organization were particularly stressful for female officers. They are more likely to be discriminated during hiring, performance evaluation, and responsibility sharing and career progression. In nutshell, workplace discrimination is a key cause of stress which curtail their creativity. On the other hand, they are considered to be equally innovative same as their male counterparts but workplace factors may limit their innovative work behavior.

Various authors have recommended to explore factors that could buffer the adverse impact of stress towards favorable outcomes (Sheldon Cohen, 1983). Previously, social, peer and supervisor support have been figured out as common neutralizers of stressful events. Spirituality and religiosity have also been endorsed as vital factor to buffer stress. This study examines the role of spirituality as moderator on the stress to IWB relationship. Muslims are perceived to be relatively more religious in nature. Therefore, spirituality in Pakistani environment may be a helpful contextual factor to mitigate stress. In sum this study is going to contribute in the following ways;

- It takes up the important topic of female discrimination in a male dominated society which needs attention from policy makers.

- It studies the buffering effects of spirituality on work place stress to IWB.

- It focuses on female population working in banking sector of Rawalpindi

- The study examines the postulated relationships in a developing country. Various authors have contended that the research implications and findings originating from the developed world cannot be generalized to developing countries by disregarding the cultural dissimilarities. There exist a strong need to examine the antecedents and outcomes of job satisfaction within different societies to understand differences and similarities. Countries and societies across the world are commonly different on account of norms, values and other cultural dimensions. Therefore, the research findings cannot be generalized to other setting particularly when the cultural dissimilarities are high (Hofstede, 1993; Drory and Vigoda-Gadot, 2010; Tsui, Nifadkar and $\mathrm{Ou}, 2007)$. Since most of the studies on job satisfaction are conducted in western and other developed countries. Therefore, this study is a contribution from the developing country with different socio-economic structure.

\section{Innovative Work Behavior}

\section{LITERATURE REVIEW}

Creativity is the term used to explain the development of new ideas while innovation has more to do with the adoption and application of useful ideas (Scott, 1994). The results of study conducted on the impact of personality traits on innovative work behavior shows that openness and willingness to experience new ideas has greater impact on individual innovative work behavior (Yesil, 2013). The concept of innovation was evolved with the structural contingency theory by Burns \& Stalker (1961) which suggested that consistent demand led to the mechanical organization while a changing demand developed the need for an organic organization which was based on innovation and creativity. In organizations, supervisors having a positive and healthy relationships with their subordinates in the form of trust and independence have shown conducive environment for innovation (Scott, 1994).

In banking sector, research has shown that equal and justified interpersonal treatment encourage innovation and creativity. Therefore, employees having higher levels of self-esteem 
are found to show more innovative capabilities than those with lower level of self-esteem (Ojedokun, 2012).

\section{Work Place Stress}

The research on workplace stress can be explained by the phenomenon of 'Burnout'. Burnout is a distinctive stress condition which includes emotional fatigue and reduced individual achievement (Cordes, 1993). It is observed that the phenomenon of workplace stress in relation to employer and employee is a complex one. However, psychological abnormality is found to be an important problem in organizations. (Tennant, 2001). Burnout is found to be common in workplace. Team work and positive employee feedback can help in keeping workers satisfied (Iacovides, 2003).

Abusive supervision can affect the employee. Therefore, eradicating all forms of abusive supervision is important and should be the prime objective of management (Harvey, 2007). It is observed that employee burnout increases with the increase in the time spent with the coworkers (Erickson, 2001).

\section{Perceived Discrimination}

Aggressive interpersonal attitudes are found to lower the level of job satisfaction and may reduce employee motivation to show innovative work behavior (Ojedokun, 2012). It has been proved empirically in the research on glass ceiling effect that the wage discrimination on the basis on gender is more pronounced on the upper side of wage distribution (Jellal, 2008). However, research also suggest that when employees are convinced with the presence of discrimination in the organization, their belief in fair promotions are decreased which also further decrease their perception for positive career growth (Foley, 2002)

\section{Perceived Discrimination Causing Workplace Stress}

Research support the evidence that female employees are found to leave an organization more often than males which is attributed to glass ceiling effects (Stroh, 1996). There is evidence suggesting strong link between job stressors and work place discrimination among female workers. This has implications not only for female workers but also the employers as work related stress affects physical and mental health thus reducing productivity (Pavalko, 2003).

Hypothesis 1: Perceived discrimination can cause work place stress.

\section{Work Place Stress Influences Innovative Work Behavior}

Role ambiguity and situational constraints should be addressed by managers as they are important stressors in workplace. In order to remove the negative effects of work stressors, organizations should provide the employees with the essential tools and technology to enhance effectiveness (Gilboa, 2008).The motivation of an employee to show innovative behavior depends on perceived self-value and anticipated fair treatment from supervisors and co-workers. Therefore enhancing organization based self-esteem and increasing fair treatment among employees can enhance their innovative work behavior (Ojedokun, 2012). Therefore, we can conclude that fair treatment and better self-esteem improves productivity. On the contrary, absence of these factors may lead to less productive and innovative work environment.

Hypothesis 2: Work place stress negatively effects innovative work behavior. 


\section{Mediating Role of Stress}

Work place stress has been used as mediator in the relationship between ethical leadership and leadership effectiveness and employee turnover intentions. It is observed that employees loyal to their leaders have lower intentions to leave job due to decreased work related stress (Elçi, 2012). In a study on mentoring and job attitudes, role stressors is used as mediator. Stressors in the form of role conflict and role ambiguity are studied and are found to be inversely related to job satisfaction and organizational commitment (Lankau, 2006). In a study on burnout resulting from inequity, the impact of job stress was studied. Wherein, it is discovered that burnout due to inequity can partly be explained in terms of job stress (Taris, 2001).

Thus the evidence supports the following hypothesis:

Hypothesis 3: Work place stress can mediate the relationship between perceived discrimination and innovative work behavior.

\section{Moderating Role of Spirituality}

In a study investigating the moderating effects of religious and spiritual factors in relation to perception of stress and psychological well-being, it is found that higher the spirituality lower will be the levels of psychological distress symptoms (Lee, 2007). Similarly a study on job overload and job satisfaction with spirituality used as moderator concluded that different dimensions of spirituality helps one in getting focused and achieving ones goals in life. Thus being satisfied makes the employees more creative and innovative (Altaf, 2011). Spirituality has significance in workplace as employees want to develop meaning through their work in terms of longing for respect and self-worth. Thus, when employees find that their spiritual needs are fulfilled, they work whole heartedly and show more commitment to the organization (Rego, 2007).

Thus, the evidence supports the following hypothesis:

Hypothesis 4: Spirituality can moderate the negative effects of workplace stress.

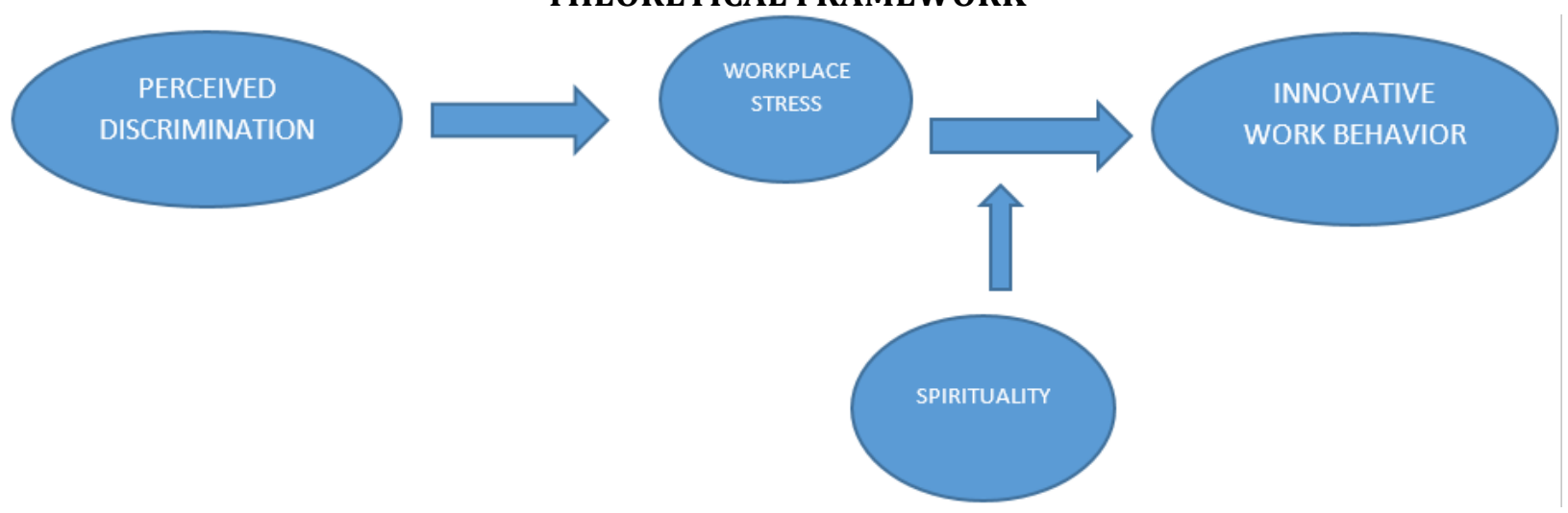

\section{Subject/Sample:}

\section{METHODOLOGY}

The purpose of this study was to examine the effects of Perceived Discrimination on Innovative Work Behavior of female employees working in different organizations. This study is confined to the females working in the officer grades as they are more vulnerable and exposed to discriminating behaviors of senior employees or supervisors while those at the senior positions are less exposed to such behaviors. Female officers may be exposed to gender discrimination from supervisors, which may in turn increase their levels of work stress and 
burnout (Martin, 1992). Haarr (1997), for example, found that female officers experienced that their male partners provided inadequate backup and often questioned about their abilities.

\section{Procedures:}

Questionnaire survey was conducted to collect the data through purposive study. The questionnaire contains information about the confidentiality and significance of the study. Data collection through questionnaire survey will be entered and analyzed using SPSS 20.0.

The data for this study has been collected from two sources; supervisors as well as subordinates, with a time lag of thirty (30) days between them for the purpose of better understanding of the Constructs of our research paper. Three hundred questionnaires were distributed with 180 returned. The final sample included one hundred and seventy (170) complete questionnaires, after removing 10 due to missing/erroneous data. In case of age, $28.8 \%$ of respondents were in the range $21-25$ years, $29.4 \%$ were in range $26-30$ years, $27.6 \%$ were in range $31-35$ years, $5.8 \%$ were in range $35-40$ years and $8.2 \%$ were above 41 years of age. As regard education level, 5.8\% were Intermediate pass, 32.3\% were bachelors while $61.7 \%$ had masters degree. With respect to years in organization, $20 \%$ had less than one year, $32.3 \%$ had $1-5$ year, $33.5 \%$ had 6-10 year and 14\% had more than ten years' experience. As regards designation in organization, $2.94 \%$ were contractual, $3.52 \%$ were grade three, $34.7 \%$ were grade two while $58.8 \%$ were grade three officers. .These demographics show thoroughly represented estimate of the population of interest.

This is a time-lag study with data collected in two time lags. Employees filled the questionnaires for perceived discrimination, stress and spirituality while supervisors filled the questionnaire about perceived discrimination and IWB.

\section{MEASURES:}

\section{Workplace Stress:}

A modified version of the College Student Life-Event Scale (CSLES) was used as a measure of stressful situations; the original scale was developed by Levine and Perkins (1980). This scale is composed of 99 items that represent events that fall into 14 different categories. Stress, the mediating variable which is caused by Perceived Discrimination will be measured with the help of this scale. The scale is based on a five point Likert Scale from 1(Never) to 5 (Very Often). Cronbach's alpha reliability of the Workplace Stress measure was .86.

\section{Innovative Work Behavior:}

The 14 items developed in our research have been adopted from the research on IWB by Kleysen and Street, (2006) based on their "Two dimensional measure on innovative work behavior". The IWB which is the Independent variable that was measured by 14 items measuring different forms of IWB reflected in the performance of employees. The scale is based on a five point Likert Scale from 1(Never) to 5 (Always). Cronbach's alpha reliability of the IWB measure was 96.

\section{Spirituality:}

The 16 item scale was developed in combination with inputs from the National Institute on Aging/Fetzer working group and is adopted from the research paper by Underwood and Teresi on Annals of Behavioral Medicine, the objective is to have a set of items to compliment other fields in the multidimensional instrument. The scale is also based on a six point Likert Scale from 1(Never or almost never) to 5 (Many times a day). Cronbach's alpha reliability of the spirituality measure was 99 . 


\section{Perceived Discrimination:}

These item are adopted from the research paper, 'Prevalence and correlates of perceived work place discrimination among older workers in USA', (Chou \& Choi, 2011).This variable is measured by the aggregate score of a scale of six items, representing six types of workplace discrimination. Examples of items include, "unfairly given jobs no one else wanted, watched more closely at job than others and co-worker with less experience and qualifications promoted before you". Each item is measured on a five-point Likert-type scale (1=never, $2=$ less than once a year, $3=a$ few times a year, $4=a$ few times a month, $5=$ once a week or more). Cronbach's alpha reliability of the PD measure was .90.

\section{ANALYSIS}

\section{RESULTS}

Table 1 Means, Standard Deviations, Correlations, and Reliabilities

\begin{tabular}{|c|c|c|c|c|c|c|c|c|c|}
\hline & & $M$ & $S D$ & 1 & 2 & 3 & 4 & 5 & 6 \\
\hline 1 & Education & 2.63 & 0.59 & 1 & & & & & \\
\hline 2 & Designation & 4.53 & 1.094 & 0.11 & 1 & & & & \\
\hline 3 & Perceived Discrimination & 2.51 & 1.12 & -0.07 & -0.03 & (0.909) & & & \\
\hline 4 & Spirituality & 4.51 & 1.03 & -0.10 & .026 & $\begin{array}{c}- \\
0.207^{* *}\end{array}$ & $(0.992)$ & & \\
\hline 5 & Stress & 3.22 & 0.55 & $0.161^{*}$ & 0.11 & $0.282 * *$ & $0.595^{* *}$ & $(0.864)$ & \\
\hline 6 & $\begin{array}{l}\text { Innovative } \\
\text { Behavior }\end{array}$ & 4.05 & 0.87 & -0.12 & $.269 * *$ & -0.09 & $.471^{* *}$ & $\begin{array}{c}- \\
0.255^{* *}\end{array}$ & $(.963)$ \\
\hline
\end{tabular}

${ }^{*} p<0.01 ; * *<<0.05 ; N=170 ;$ Cronbach's alpha presented in parenthesis

Table 2. Results of hierarchical regression analyses.

Mediator Variable : STRS

Predictors

$\beta \quad \mathbf{R}^{2} \quad \Delta \mathbf{R}^{2}$

Dependent Variable : IWB

$\begin{array}{lllllll}\beta & \mathbf{R}^{2} & \Delta \mathbf{R}^{2} & \beta & \mathbf{R}^{2} & \Delta \mathbf{R}^{2}\end{array}$

Direct Effects

Step-I

Control Variables

0.033

0.093

Step-II

PD

$0.299 * * *$

0.122

$-0.099$

0.102

Indirect Effects

Step-I

Control Variables

0.093

Step-II

STRS

$-.265 * *$

0.164

Step-III

PD

$-0.019$

0.164

Note. $N=170 . P D=$ Perceived Discrimination; STRS = Stress, IWB= Innovative Work Behavior

$* p<0.05 ; * * p<0.01 ; * * *<0.001$ 


\begin{tabular}{lll}
\hline & \multicolumn{2}{c}{ Innovative Work Behavior } \\
\cline { 2 - 3 } & \multicolumn{1}{c}{$\boldsymbol{\Delta \boldsymbol { R } ^ { 2 }}$} \\
\hline Step 1 & -.125 \\
$\quad$ Education & $.286^{* * *}$ \\
$\quad$ Designation & -.097 \\
Step 2 & $.268^{* * *}$ \\
$\quad$ Education & .003 \\
Designation & $.455^{* * *}$ \\
Stress & \\
Spirituality & -.092 \\
Step 3 & $.233^{* * *}$ \\
Education & $-.338^{* *}$ \\
Designation & -.097 \\
Stress & $.536^{* * *}$ \\
Spirituality & \\
STRSXSPRTY & \\
\cline { 2 - 3 }
\end{tabular}

Note. $N=170$. STRS = Stress; SPRTY = Spirituality; IWB = Innovative Work behavior.

${ }^{*} p<0.05 ; * * 0.01 ; * * * 0.001$

Table 1 shows the descriptive statistics, bivariate correlations and the alpha reliabilities. Table 2 shows the regression analysis for mediation.

\section{Descriptive Statistics and Correlations:}

Table 1 shows the descriptive statistics, bivariate correlations, and the alpha reliabilities. Correlations of Stress with PD was ( $r=0.282, p<0.05)$, with Spirituality $(r=-0.59, p<0.05)$, thus significant and in expected directions. Correlations of IWB with PD ( $r=-0.09$, n.s.), with spirituality $(r=0.47, p<0.05)$ and with stress $(r=-0.25, p<0.05)$, were also in expected directions.

Our first hypothesis states that perceived discrimination causes workplace stress. Results in the table supports the hypothesis as a positive relation is found between perceived discrimination and workplace stress as indicated by regression coefficient $(\beta=0.299, p<$ 0.001). Our second hypothesis states that workplace stress negatively affects innovative work behavior. Results in Table 2 supports this hypothesis by showing a negative and significant relation between stress and innovative work behavior as indicated by regression coefficient $(\beta=-0.265, p<0.01)$.

Our third hypothesis states that workplace stress can mediate the relationship between perceived discrimination and innovative work behavior. In order to verify this relationship, a four step Barren and Kenny (1986) method was adopted. In the first step PD was regressed with IWB and the relationship was insignificant $(\beta=-0.099, p=0.184)$. In second step, PD was regressed with stress and the relationship was found to be significant $(\beta=0.299, p<0.001)$. In the third step, the mediating variable stress was regressed with IWB and a significant negative impact was found $(\beta=-0.265, p<0.01)$. In the fourth and final step regression was performed when PD was regressed with IWB controlling the impact of stress and an insignificant impact was found $(\beta=-0.019, P>0.05)$. 
Table 3 shows the results of moderation analysis. Moderated regression analysis (Cohen et al. 2003) was used to test our fourth Hypotheses that spirituality moderates the negative impact of workplace stress. For this purpose, we centered the independent and moderating variables. Education and designation as control variable were entered in the first step. Independent and moderating variables were entered in the second step. In the third step, product terms of independent and moderator variables (Stress*Spirituality) were entered, which if significant confirmed moderation. Results in Table 2 show that the interaction term was significant showing ( $\beta=0.536, p<0.001)$, thus confirming moderation test. Thus our fourth hypothesis is proved wherein spirituality moderates the relationship between stress and IWB.

\section{DISCUSSION}

The objective of the study is to explore a relationship between perceived discrimination and innovative work behavior mediated by workplace stress. The moderation effect of spirituality was tested in order to buffer the negative effects of stress on innovative work behavior. This study is inspired from past researches as well as real time experience. In past researches the impacts of glass ceiling on the wage distribution have shown its effects on upper or managerial level employees (Jellal, 2008). This has focused our research to explore the impact of gender discrimination in lower level female employees. Foley (2002) suggest that perceived discrimination among employees decrease their belief in fair and justified promotion system and consequently influencing their career growth. Thus, a positive career growth in an evolving organization requires changes, creativity and innovation to meet the pace of other organizations. In a country like Pakistan, the glass ceiling effects are found to be more pronounced among females working in non-managerial position. However, in order to study these observations, a research was conducted and the relationship was explored empirically. The purpose of this research was to explore if PD in workplace leads to stress which is supported by past evidences wherein female turnover was found to be related to glass ceiling effects (Stroh, 1996). Similarly we were interested to find if the corresponding stress further effects productivity. (Pavalko, 2003) found that workplace stress effects physical and mental health which reduces productivity and output. However, in a relatively religious society of Pakistan, spirituality can mitigate the negative effects of stress. (Rego, 2007) found that spiritually satisfied workers can be more productive and committed to the organization.

The results of the current research show a positive and significant relationship between Independent variable, Perceived Discrimination and the Mediator, Workplace Stress. These results support the past studies where a significant relation exists between job stressors and work place discrimination among female workers (Pavalko, 2003). While a Negative and significant relation is found between the mediator Stress and dependent variable Innovative work behavior. This result supports the evidence that Burnout which is a form of emotional fatigue reduces individual achievement (Cordes, 1993).

The results of moderation test show a significant value of spirituality jointly effecting with stress on Innovative work behavior. This result supports the past research wherein the spiritually strengthens employees making them more satisfied and focused in their job resulting in more creativity and innovative work behavior (Altaf, 2011). The significant value of interacting variables stress and spirituality is also in line with past researches wherein it is found that spirituality can mitigate the psychological distress symptoms (Lee, 2007).

In comparing our unique setting of organization in Pakistan with that of a Western organization, we assume that the findings can be generalized in other more developed 
economies as the perceived discrimination is found to be particularly low in this urbanized area of Pakistan. However, we couldn't find any past study with the same variables.

\section{Theoretical Implications:}

Direct relationships are also your contribution, as it helps to extend applicability of existing established relationships. The current study has contributions to the existing researches conducted in the same area. First we have explored the relationship of perceived discrimination with workplace stress and the findings confirm a negative relationship. Second, we conceptualized the effects of stress on innovative work behavior with the moderating or buffering effects of spirituality. The findings show that spirituality can buffer or lower the negative influence of stress on innovative work behavior.

\section{Practical Implications}

The current study has implications on the managers or supervisors in the banking industry. The study brings attention to the discrimination faced by the female junior level staff. If they are treated fairly, they can show better motivational levels and can show better results in the form of more creativity and innovation. However, as psychological abnormality or stress is found to be an important problem in organizations (Tennant, 2001), spirituality can help the females cope with the negative effects of emotional stress.

Practical implications to the managers include efforts to help cope the female staff with discriminating practices so that females are free from stress and perform at par with their male counterparts. Also spirituality must be appreciated at workplace by hiring spiritually high staff and provide trainings to inculcate spirituality. Thus top management must inculcate more justified rules and regulations in their policies.

\section{Strengths, Limitations and Future Directions}

The study has focused on the female staff working in lower or subordinating positions in banking sector, thus being more vulnerable to discriminating behaviors by the supervisors. This if applied practically, this study can have long lasting implications.

There are some limitations in this study as it focused the females in banking in the area of Rawalpindi. Thus the scope of this research is limited to the geographical location and female population of the locality. The research is based on cross sectional data and therefore has its limitations. Some of the measures were self-reported therefore there are chances for common method biasness

The future researches should include a wider geographical area and include a bigger population. As Pakistan has a unique culture and society values, therefore more researches should be conducted on the employee issues of this geographical location.

Future studies may be conducted with other mediator such as burnout or psychological distress in order to explore the effects of PD on mental health. Similarly other possible moderators may include social support, religiosity and environment. Future researches should include actual reading about reported cases of discrimination. Longitudinal study should be conducted in order to obtain more precise results.

\section{References}

Altaf, A. and M. A. Awan (2011). "Moderating effect of workplace spirituality on the relationship of job overload and job satisfaction." Journal of business ethics 104(1): 93-99. 
Malik, S.F. (2016). Impact of Perceived Discriminiation and Resultatnt Stress on Innvative Work Behavior Moderated by Spirituality among Female Employees in Private Banks of Rawalpindi. Archives of Business Research, 4(6), 389-399.

Cordes, C. L. and T. W. Dougherty (1993). "A review and an integration of research on job burnout." Academy of management review 18(4): 621-656.

Cohen, S., et al. (1983). "A global measure of perceived stress." Journal of health and social behavior: 385-396.

Elçi, M., et al. (2012). "The impact of ethical leadership and leadership effectiveness on employees' turnover intention: The mediating role of work related stress." Procedia-Social and Behavioral Sciences 58: 289-297.

Erickson, R. J. and C. Ritter (2001). "Emotional labor, burnout, and inauthenticity: Does gender matter?" Social Psychology Quarterly: 146-163.

Foley, S., et al. (2002). "The perceived glass ceiling and justice perceptions: An investigation of Hispanic law associates." Journal of management 28(4): 471-496.

Gilboa, S., et al. (2008). "A meta-analysis of work demand stressors and job performance: examining main and moderating effects." Personnel Psychology 61(2): 227-271.

Harvey, P., et al. (2007). "Coping with abusive supervision: The neutralizing effects of ingratiation and positive affect on negative employee outcomes." The Leadership Quarterly 18(3): 264-280.

Hon, A. H., et al. (2013). "Overcoming work-related stress and promoting employee creativity in hotel industry: The role of task feedback from supervisor." International Journal of Hospitality Management 33: 416-424.

Iacovides, A., et al. (2003). "The relationship between job stress, burnout and clinical depression." Journal of affective disorders 75(3): 209-221.

Jellal, M., et al. (2008). "Evidence on the glass ceiling effect in France using matched worker-firm data." Applied Economics 40(24): 3233-3250.

Kanter, R. 1983. The change masters. New York: Simon \& Schuster.

Kanter, R. 1988. When a thousand flowers bloom: Structural, collective, and social conditions for innovation in organizations. In B. M. Staw \& L. L. Cummings (Eds.), Research in organizational behavior, vol 10: 169-211. Greenwich, CT: JAI Press.

Lankau, M. J., et al. (2006). "The mediating influence of role stressors in the relationship between mentoring and job attitudes." Journal of Vocational Behavior 68(2): 308-322.

Lee, B.-J. (2007). "Moderating effects of religious/spiritual coping in the relation between perceived stress and psychological well-being." Pastoral Psychology 55(6): 751-759.

Martin, J. J., et al. (1999). "A model of stress and burnout in male high school athletic directors."

Morash, M. and R. N. Haarr (1995). "Gender, workplace problems, and stress in policing." Justice Quarterly 12(1): $113-140$.

Ojedokun, O. (2012). "Role of perceived fair interpersonal treatment and organization-based self-esteem in innovative work behavior in a Nigerian bank." Psychological Thought 5(2): 124-140.

Pavalko, E. K., et al. (2003). "Does perceived discrimination affect health? Longitudinal relationships between work discrimination and women's physical and emotional health." Journal of health and social behavior: 18-33.

Stroh, L. K., et al. (1996). "Family structure, glass ceiling, and traditional explanations for the differential rate of turnover of female and male managers." Journal of Vocational Behavior 49(1): 99-118.

Tennant, C. (2001). "Work-related stress and depressive disorders." Journal of psychosomatic research 51(5): 697-704.

Taris, T. W., et al. (2001). "From inequity to burnout: The role of job stress." Journal of Occupational Health Psychology 6(4): 303.

Rego, A., et al. (2007). "Workplace spirituality, commitment, and self-reported individual performance: An empirical study." Management Research: Journal of the Iberoamerican Academy of Management 5(3): 163-183.

Scott, S. G. and R. A. Bruce (1994). "Determinants of innovative behavior: A path model of individual innovation in the workplace." Academy of management journal 37(3): 580-607.

Van de Ven, A. 1986. Central problems in the management of innovation. Management Science, 32: 590-607. 
Van de Ven, A. H. and H. L. Angle (1989). Suggestions for managing the innovation journey, Strategic Management Research Center, University of Minnesota.

Yesil, S. and F. Sozbilir (2013). "An empirical investigation into the impact of personality on individual innovation behaviour in the workplace." Procedia-Social and Behavioral Sciences 81: 540-551 